\title{
Dietary factors and risk of mortality among patients with esophageal cancer: a systematic review
}

\author{
Li-Ping Sun ${ }^{1}$, Lu-Bin Yan², Zhen-Zhen Liư ${ }^{3}$, Wen-Jing Zhao ${ }^{4}$, Cai-Xia Zhang ${ }^{1}$, Yu-Min Chen ${ }^{1}$, Xiang Qian Lao ${ }^{5}$ and
} Xudong $\mathrm{Liu}^{1 *}$

\begin{abstract}
Background: The effects of dietary factors on prognosis of esophageal cancer remain unclear. This systematic review and meta-analysis aimed to assess the association between dietary intake and the risk of mortality among patients with esophageal cancer.

Methods: Six electronic databases (PubMed, Web of Science, OVID, ProQuest, CNKI and Wanfang) were searched for studies published up to Oct. 2019 that examined the association between dietary intake and all-cause mortality, esophageal cancer-specific mortality and esophageal cancer recurrence. The pooled hazard ratio (HR) with 95\% confidence interval $(\mathrm{Cl})$ were derived by comparing the highest with the lowest categories of each dietary item and by using random effect models.

Results: A total of 15 cohort studies were included in this study and all reported pre-diagnosis dietary exposure; two focused on dietary folate, 12 on alcohol consumption and three on other dietary components (sugary beverages, phytochemicals and preserved vegetables). When comparing the highest with the lowest categories, dietary folate intake was associated with a reduced risk of esophageal cancer-specific mortality in patients with esophageal squamous cell carcinoma (HR: $0.41,95 \% \mathrm{Cl}: 0.25-0.69)$, with low heterogeneity $\left(P^{2}=0 \%, P=0.788\right)$. When comparing the highest with the lowest categories of alcohol consumption, alcohol consumption was associated with an increased risk of all-cause mortality in patients with esophageal squamous cell carcinoma (HR: 1.29, 95\% Cl: 1.07-1.55; heterogeneity: $P^{2}=53 \%, P=0.030$ ), but this increased risk was not significant in patients with esophageal adenocarcinoma ( $H R=1.05,95 \% \mathrm{Cl}: 0.84-1.32)$.

Conclusions: This review with pre-diagnostic dietary exposure showed that dietary folate intake was associated with a reduced risk of mortality of esophageal squamous cell carcinoma, whereas alcohol consumption was associated with an increased risk. More studies are needed to investigate effect of dietary factors, especially postdiagnosis dietary consumption, on esophageal cancer prognosis.
\end{abstract}

Keywords: Dietary intake, Esophageal Cancer, Mortality, Systematic review, Meta-analysis

\footnotetext{
* Correspondence: liuxudong@mail.sysu.edu.cn

${ }^{1}$ Department of Epidemiology, School of Public Health, Sun Yat-sen University, Guangzhou, China

Full list of author information is available at the end of the article
}

(c) The Author(s). 2020 Open Access This article is licensed under a Creative Commons Attribution 4.0 International License, which permits use, sharing, adaptation, distribution and reproduction in any medium or format, as long as you give appropriate credit to the original author(s) and the source, provide a link to the Creative Commons licence, and indicate if changes were made. The images or other third party material in this article are included in the article's Creative Commons licence, unless indicated otherwise in a credit line to the material. If material is not included in the article's Creative Commons licence and your intended use is not permitted by statutory regulation or exceeds the permitted use, you will need to obtain permission directly from the copyright holder. To view a copy of this licence, visit http://creativecommons.org/licenses/by/4.0/. The Creative Commons Public Domain Dedication waiver (http://creativecommons.org/publicdomain/zero/1.0/) applies to the data made available in this article, unless otherwise stated in a credit line to the data. 


\section{Background}

Esophageal cancer (EC) is one of the most malignant tumors worldwide, ranking seventh in cancer incidence and sixth in cancer mortality in 2018 [1]. Esophageal adenocarcinoma (EAC) and esophageal squamous cell carcinoma (ESCC) are two main histological types. EAC is the main histological type in developed countries whereas ESCC predominates in eastern Asia and Africa [2]. The prognosis of esophageal cancer is poor; the 5year survival rate of EC in the United States is 19\%, in Europe $12.4 \%$, and in China 20.9\% [3-5].

The prognosis of esophageal cancer is influenced by many different factors [6]. Noteworthy, increasing evidence is highlighting the pivotal effects of nutritional factors on cancer prognosis and survival: natural ingredients such as lycopene and beta-carotene in the plant food could inhibit EC109 cell viability [7], dietary interventions could improve diet quality in cancer survivors [8], and nutritional support could improve esophageal cancer prognosis by improving treatment compliance, reducing toxicity and enhancing the immune response [9]. However, most studies focused on the roles of perioperative nutrition support in postoperative complications $[10,11]$, and the results from epidemiological studies on the associations between dietary factors and EC prognosis are inconclusive [12-15]. A meta-analysis showed that pre-diagnosis alcohol drinking increased risk of death in ESCC rather than in EAC [16], however, some new evidence has emerged after this study published and the pooled results are needed to be updated.

Therefore, by summarizing the results of observational studies, this systematic review and meta-analysis was conducted to evaluate the association between food and its components intake and risk of mortality among patients with esophageal cancer, with addressing the difference in histology and the difference between allcause mortality and cancer-specific mortality.

\section{Methods}

Literature search

Literatures published up to October. 2019 were systematically searched through four English databases (PubMed, Web of Science, OVID, ProQuest) and two Chinese databases (CNKI and Wanfang). PRISMA statement for conducting and reporting meta-analysis of observational studies was followed [17]. The search strategy was as follows: [(vegetables OR fruits OR meat OR poultry OR drinking OR alcohol OR beer OR liquor OR beverage OR nuts OR soy OR cereal OR bean OR nutrients OR micronutrients OR macronutrients OR dietary fiber OR vitamin OR phytochemicals OR lignan OR phytoestrogen OR dietary OR diet OR food OR dietary pattern OR dietary supplements)] AND [(esophageal cancer OR esophageal adenocarcinoma OR esophageal squamous cell carcinoma
OR esophageal neoplasm OR esophageal tumor OR cancer of esophagus OR esophageal neoplasms)] AND [(Survival OR prognosis OR mortality OR recurrence OR replase OR progression OR medical futility OR treatment outcome OR treatment failure OR cause of death OR fatal outcome)]. Language and countries were not restricted during the whole searching process.

Two researchers (LP Sun \& LB Yan) independently conducted the literature retrieval, identified potential studies, extracted information from the included papers, and assessed the quality of included studies. Discrepancies were settled down by group discussion with other two professionals (X LIU \& CX Zhang). The titles and abstracts of initially identified papers were firstly reviewed, and then the full texts of the selected papers were reviewed to determine eligibility. To avoid omission of literatures, backward and forward citation tracking in both Web of Science and Scopus were also used to identify articles.

\section{Study selection criteria}

Studies meeting the following conditions would be included: (i) study design was cohort study with esophageal cancer patients; (ii) the consumption of food and/or its components but not supplementations was accessible; (iii) prognostic outcomes included all-cause mortality, esophageal cancer-specific mortality or esophageal cancer recurrence; (iv) the hazard ratio (HR) or relative risk with $95 \%$ confidence interval (95\% CI) were reported or could be calculated. When there were papers from the same study or covering the same population, only the most comprehensive or latest data was selected. Case reports, cross-sectional studies, editorials, abstracts, reviews, articles without full text, duplicated studies, animal studies and vitro studies were excluded.

\section{Data extraction}

Data and information were extracted from the included studies, including name of the first author, publication year, country, sources of patients, sample size, histological type, follow-up duration, stage/grade grouping, dietary exposure, dietary assessments, outcomes, comparison method, effect size, confounders and covariates.

\section{Quality assessment}

Quality of the included papers was evaluated according to the Newcastle-Ottawa Scale (NOS) Criteria for nonrandomized studies [18]. A maximum total 9 points were assigned to each study, with a maximum of 4 for selection, 2 for comparability and 3 for outcome. Studies were considered to be of high quality $(>6)$, median quality $(4 \sim 6)$ or low quality $(\leq 3,[19])$. 


\section{Statistical analyses}

Meta-analysis was conducted to estimate the pooled HR with $95 \%$ CI by comparing the highest with the lowest categories of dietary intake in each selected item. A random effect model was selected in the meta-analysis [20]. Heterogeneity between studies was measured using $Q$ and $I^{2}$ statistics. Sensitivity analysis was conducted by excluding the study one by one from the pooled results, by excluding the studies not reporting adjusted effects, and by excluding the studies not collecting information of stage and severity of esophageal cancer. The metaanalysis with crude HRs obtained from univariate analysis was also conducted. Publication bias was tested by funnel plot with Begg's tests [21]. A power calculator used to estimate statistical power of meta-analyses [22]. Statistical analysis was completed in Stata 15.1 (Stata Corporation, College Station, TX) and R software (version 3.5.3).

\section{Results}

\section{Literature retrieval}

Figure 1 shows the flowchart of literature selection. After removal of 4215 duplicates, 3795 potentially eligible records were left, of which 3677 were excluded after reviewing the titles and abstracts. Finally, 15 eligible cohort studies [12-15, 23-33] containing 6826 esophageal cancer patients were identified through full text review of 118 studies. The most common reasons for exclusion were study designs, lack of data on dietary exposure and no outcomes of interest.

\section{Characteristics of included studies}

Characteristics and study quality of the included studies are shown in Table 1. Briefly, 7 cohort studies recruited patients from completed case-control studies [12-14, 23, $29,31,32]$ and the other eight were new established cohorts [15, 24-28, 30, 33]; three studies were conducted in USA [12, 13, 23], six in China [15, 24, 25, 27, 30, 32], two in Australia [29, 31], one in South Korea [28], one in Sweden [14], one in Japan [26] and one in Iran [33]; one study only recruited male patients [28] and the others included both genders. The median follow-up duration ranged from 0.8 to 12.1 years. Only three studies reported the risk estimates without any adjustments [23-25], other 12 studies reported adjusted risk estimates. The most common adjusted confounders included age, gender, tumor stage, complications and treatments. With the exception of five studies [23-25, $28,30]$, other ten studies collected information of stage and severity of esophageal cancer and adjusted for them when estimating the effect size. Eleven studies focused on ESCC [13-15, 23-27, 29, 30, 32], 5 on EAC [12-14, $23,31]$, and 3 on EC [12, 28, 33].
All of 15 included studies provided pre-diagnosis dietary exposure information. In terms of types of dietary exposure, 12 studies were on alcohol consumption [14, 15, 23-29, 31-33], two on dietary folate intake [24, 25], one on sugary beverage [12], one on flavonoids and lignans [13] and one on preserved vegetables [30]. A total of 13 studies [12-15, 23, 26-33] used all-cause mortality as outcome and the other two $[24,25]$ used esophageal cancer-specific mortality. Consumption of alcohol was measured using health behavior questionnaires, while intakes of dietary folate, flavonoids, preserved vegetables and sugary beverages were collected from validate modified food frequency questionnaire. Of the five studies not collecting information of stage and severity of esophageal cancer, one was focused on preserved vegetables [30] and the other four on alcohol [23-25, 28].

For study quality of 15 included studies, average NOS score was 6.65 , ranging from 4 to $8 ; 12$ studies were high quality (NOS score $\geq 7$ ) and three studies were median quality.

\section{Dietary folate intake}

Only two studies [24, 25] reported effects of dietary folate intake on esophageal cancer-specific mortality in ESCC. These two studies provided adjusted risk estimates from multivariate analysis. Categorization of folate intake was different in these two studies. The highest vs. the lowest in one article [24] was $\geq 95.5 \mu \mathrm{g} /$ day vs. $<30.0 \mu \mathrm{g} /$ day, while in another article [25] was $>300 \mu \mathrm{g} /$ day vs. $<230 \mu \mathrm{g} /$ day. When pooled these two studies (Fig. 2), the overall HR was 0.41 (95\% CI: $0.25-0.69)$ with low statistical heterogeneity $\left(P_{\text {for heterogeneity }}=0.79, I^{2}=0 \%\right)$. The funnel plot did not reveal asymmetry (Fig. 3 ) and the corresponding Begg's test did not show publication bias $(P=1.00)$. Power calculation for random effect model was $96.5 \%$.

\section{Other dietary components}

Only one study on sugary beverages [12], one on phytochemicals [13] and one on preserved vegetables [30] were found. Miles et al. [12] studied effects of sugary beverages intake on prognosis of EC and EAC. They found that soft drinks and fruit juices intake would worsen prognosis of EC patients; however, when the study population was restricted to patients with EAC, no significant association between sugary beverages and allcause mortality was found. Petrick et al. [13] studied effects of consumption of total dietary flavonoids, dietary flavonoid subclasses (anthocyanidins, flavan-3-ols, flavanones, flavones, flavonols and isoflavones) and lignans on all-cause mortality in ESCC and EAC, respectively; however, only lignans was found to reduce all-cause mortality of ESCC by $42 \%(\mathrm{HR}=0.58$, 95\% CI: $0.37-$ 0.92). As indicated in a study done by Shi et al. [30], in ESCC patients, when comparing with patients 


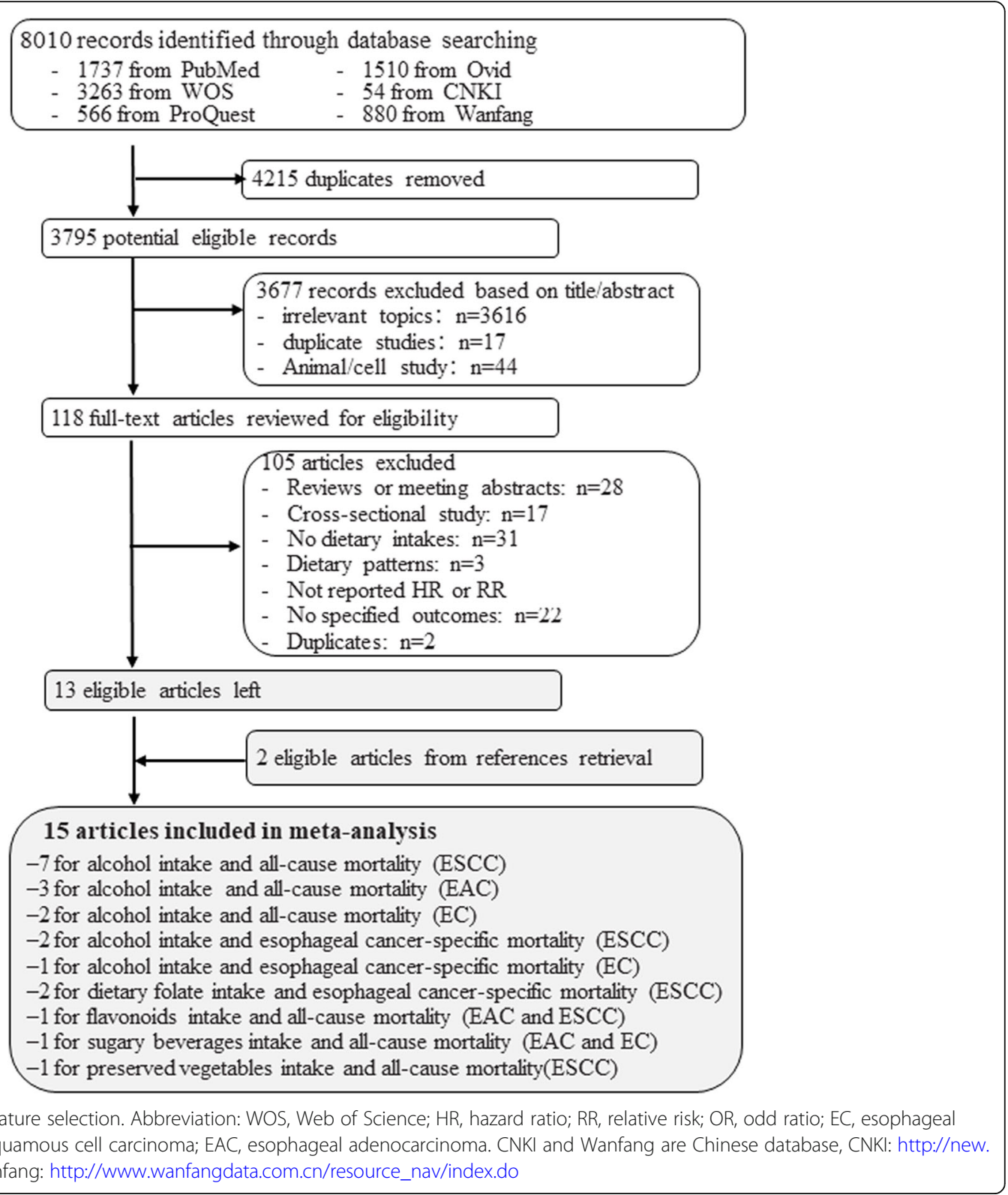

consuming preserved vegetables $<1$ time/week, those who consumed preserved vegetables $\geq 1$ time/week had a 1.58 -fold (95\% CI: 1.01-2.47) risk of all-cause mortality.

\section{Alcohol consumption}

A total of ten studies [14, 15, 23, 26-29, 31-33] investigated effects of alcohol consumption on all-cause mortality and the other two studies $[24,25]$ on esophageal cancer-specific mortality (Table 1 ). The reference group (the lowest group) in nine studies $[14,15,23-25$, $27,28,32,33]$ was non-drinkers, in two studies $[29,31]$ was those consuming $<10 \mathrm{~g}$ ethanol per week, and in one study [26] was non-heavy drinkers. The highest group was defined as ever drinkers [23, 24], or current drinkers [15, 32, 33], or group with the highest level of alcohol consumption [14, 25-29, 31]. Only five studies $[23-26,29]$ was available to estimate the risk by using univariate analysis (Table 2).

The pooled results of the association between alcohol consumption and risk of death among different subtypes of esophageal cancer are shown in Fig. 4. When comparing the highest with lowest consumption of alcohol, the pooled HR was 1.48 (95\% CI: 1.19-1.84) with low statistical heterogeneity $\left(P_{\text {for heterogeneity }}=0.35, I^{2}=4.2 \%\right)$ in EC and 1.29 (95\% CI: 1.07-1.55) with moderate statistical heterogeneity $\left(P_{\text {for heterogeneity }}=0.03, I^{2}=53.0 \%\right)$ in ESCC, whereas no association was found in EAC (HR = 1.05, 95\% CI: 0.84-1.32). The funnel plots did not show 


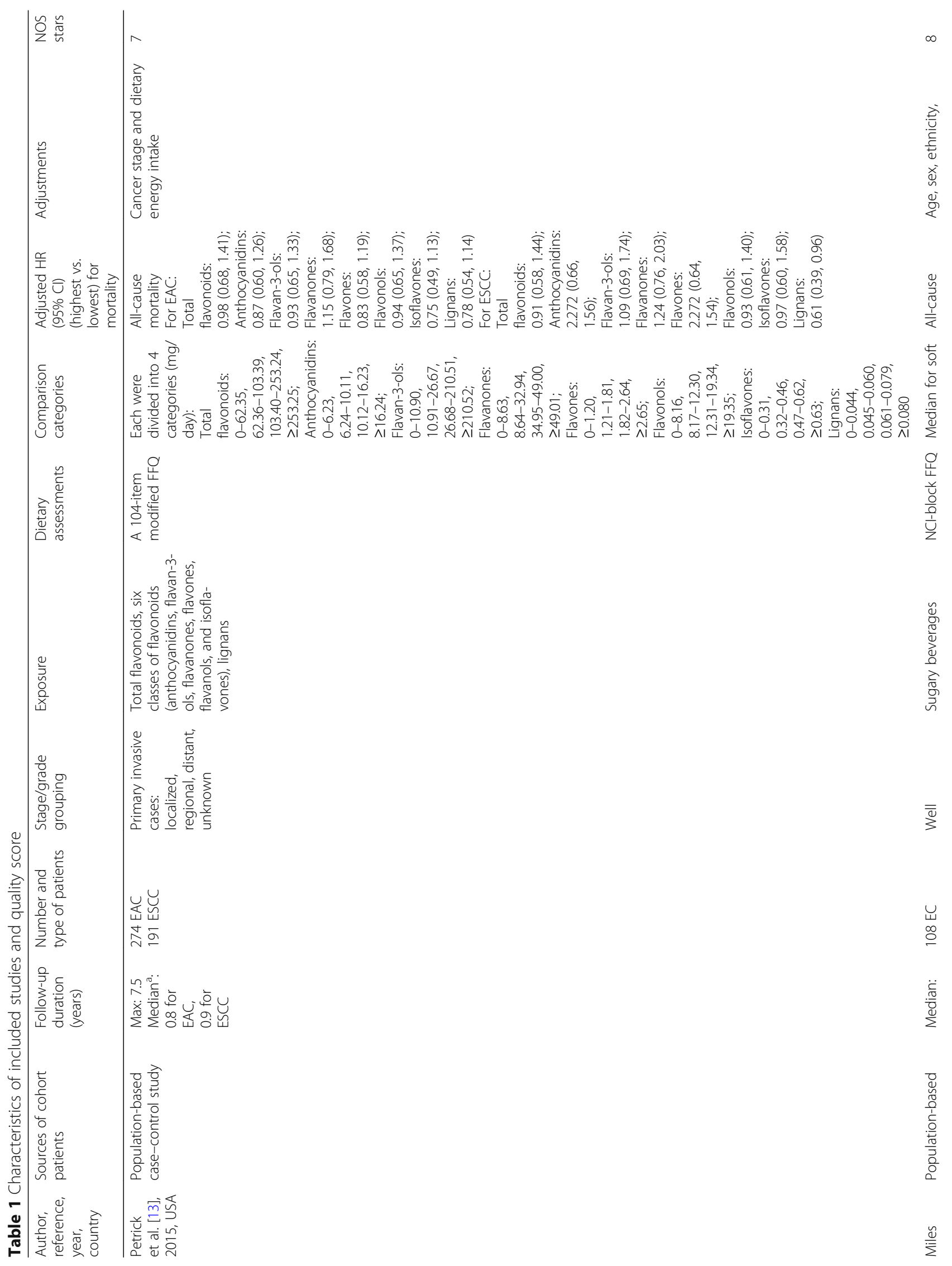




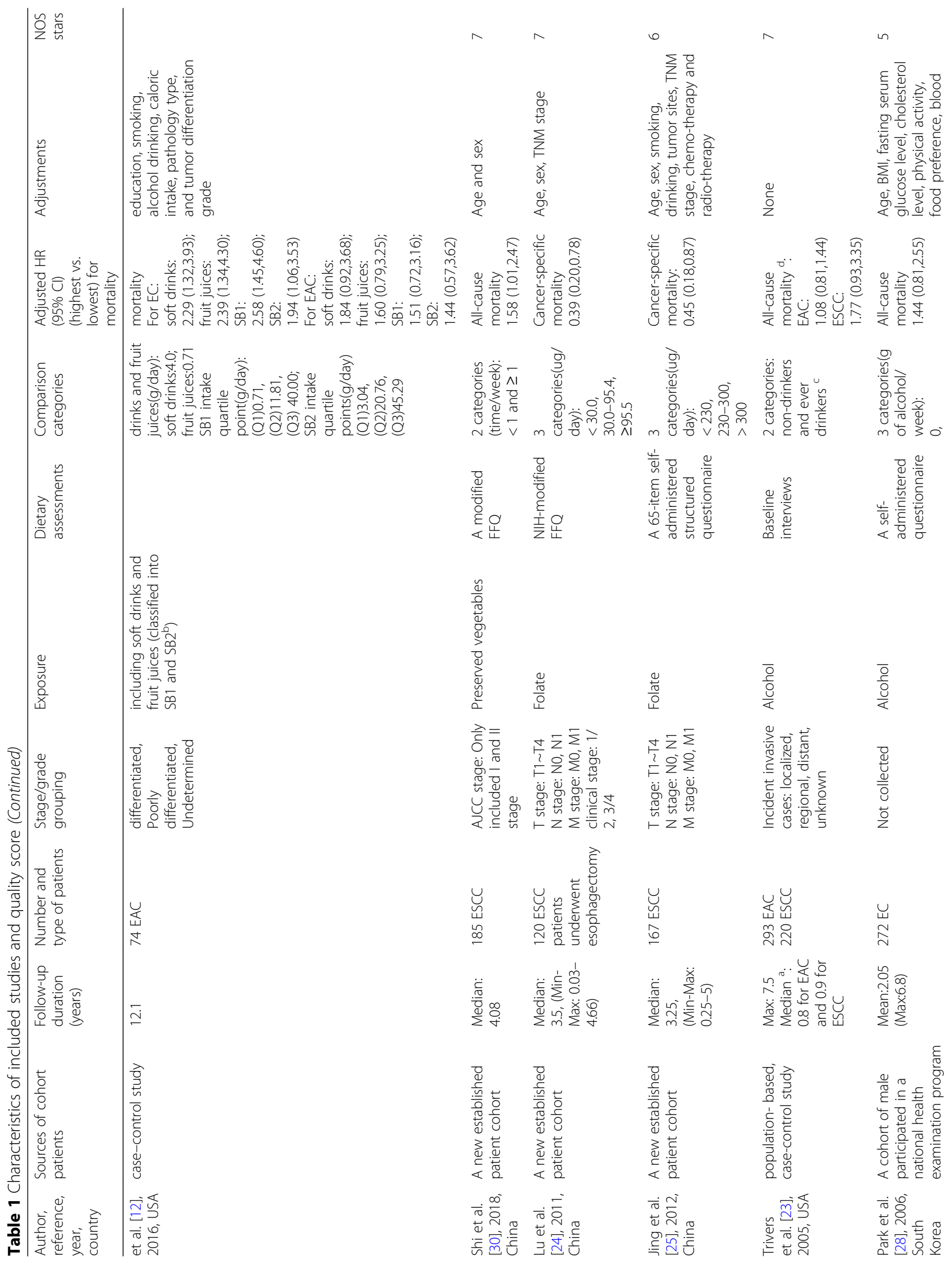




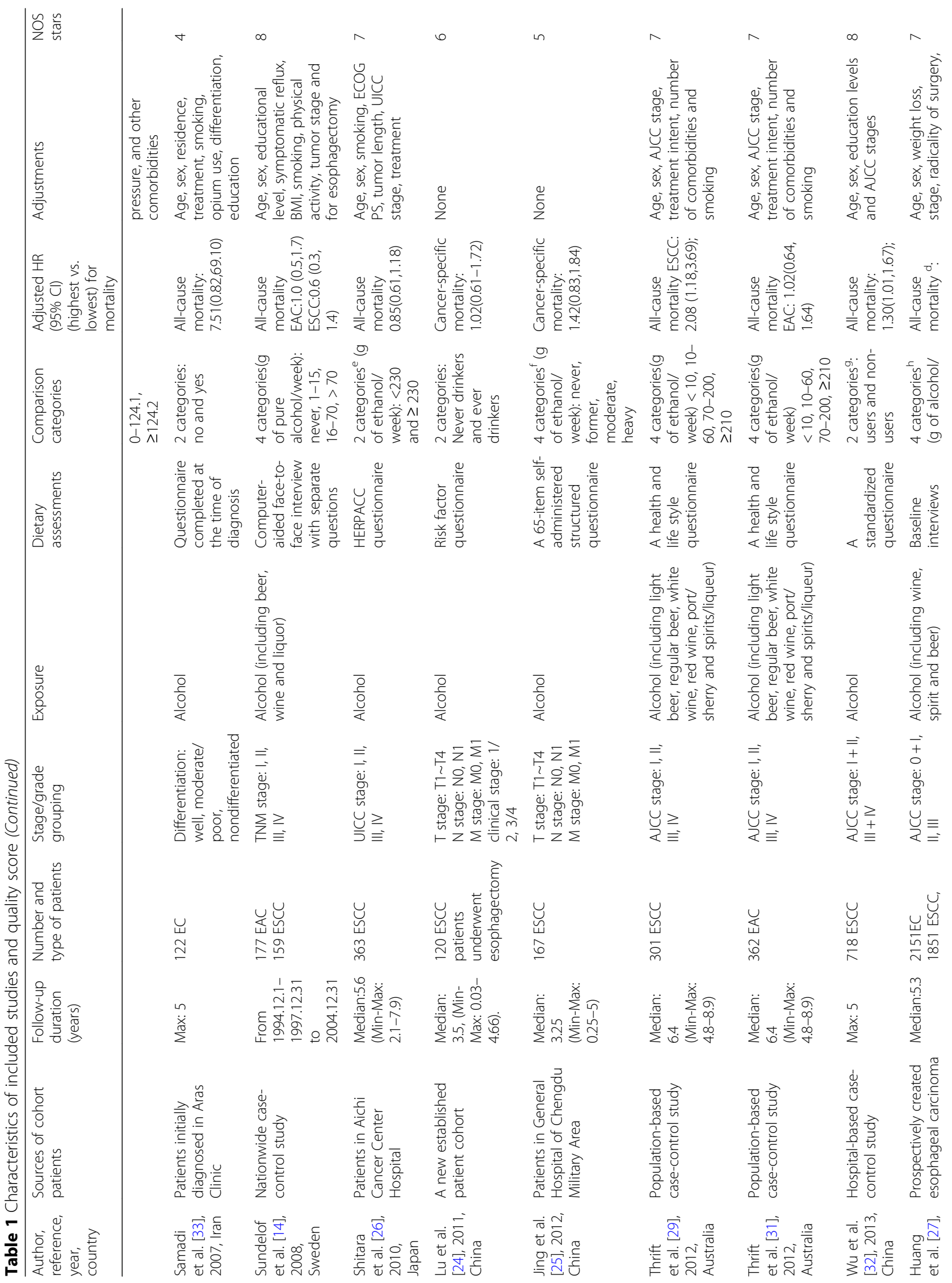




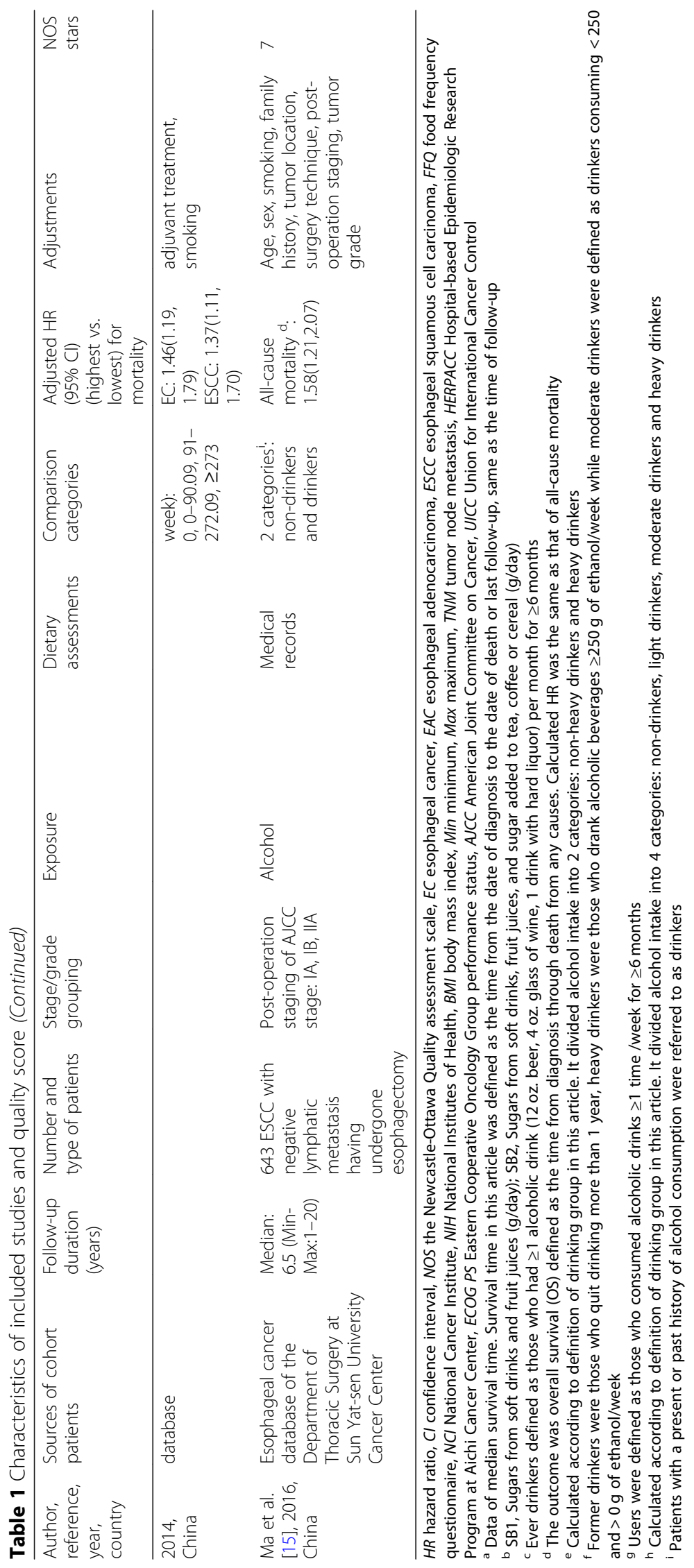




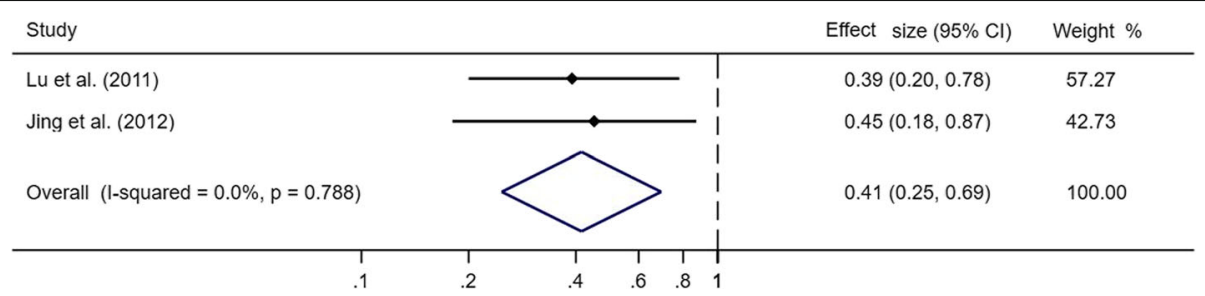

Fig. 2 Forest plot of association between dietary folate intake (highest vs. lowest) and esophageal cancer-specific mortality among patients with esophageal squamous cell carcinoma

significant asymmetry for any types of esophageal cancer (Fig. 5), and the corresponding Begg's tests did not show publication bias (all $P>0.30$ ). Power calculation for these three random effect models was all equal to $100.0 \%$.

The sensitivity analysis was only performed on alcohol consumption. The analysis was repeated consecutively by removing one study from the pooled results each time, and significant change was observed only after the exclusion of Huang's study [27] in EC and ESCC, respectively (Supplementary Fig. S1); the analysis was also conducted by excluding 3 studies [23-25] not reporting adjusted effect size, and the pooled results were 1.26 (95\% CI: 1.01-1.60) for ESCC and 1.01(95\% CI: 0.701.47) for EAC (Table 2). When the unadjusted effect was considered, the pooled HR was 1.27 (95\% CI: 1.06-1.53) for ESCC. Only one study [23] on EAC provided crude effect; hence, the pooled analysis was not conducted (Table 2). When the studies which did not include information of stage and severity of esophageal cancer were excluded, the pooled HR was 1.26 (95\% CI: 1.01-1.60) for ESCC and 1.01(95\% CI: 0.70-1.47) for EAC.

\section{Discussion}

As far as we know, there lacks of systematic review with quantitative analysis to evaluate ordinary dietary

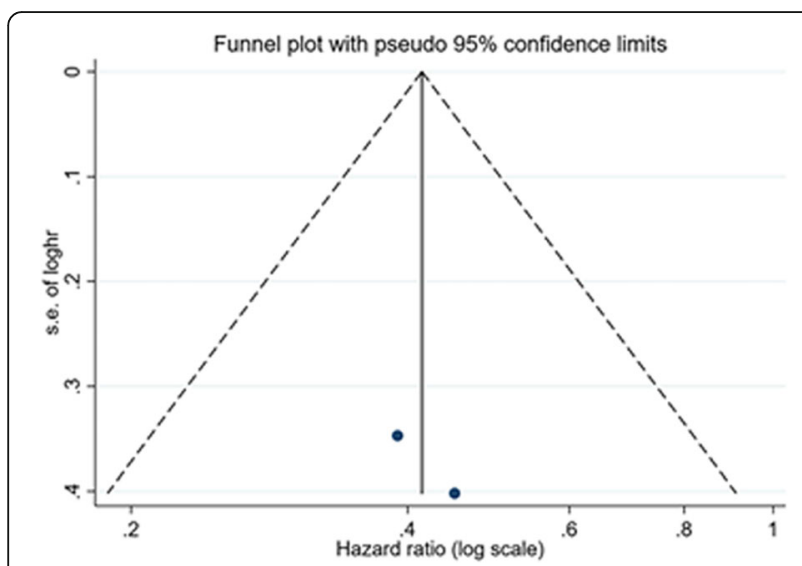

Fig. 3 The funnel plot with Pseudo 95\% confidence limits on dietary folate intake and esophageal cancer-specific mortality among patients with esophageal squamous cell carcinoma behavior and prognosis of esophageal cancer. The results from meta-analysis displayed that pre-diagnostic dietary folate intake was significantly related to a decreased risk of esophageal cancer-specific mortality in ESCC and prediagnostic alcohol consumption was associated with an increased risk of all-cause mortality in EC and in ESCC.

Alcohol is one of the major determinant factors for developing esophageal cancer [34], but effects of it on esophageal cancer prognosis remain controversial [16]. The pooled results in our study showed that prediagnostic alcohol consumption could increase risk of mortality among EC and ESCC patients by 48 and 29\% respectively; however, this effect was not found in EAC patients. Without adjustments, confounding factors could lead to misinterpretation of the association between independent variables and dependent variables [35]. Hence, we pooled crude HRs obtained from univariate analysis and adjusted HRs obtained from multivariate analysis, respectively; the association remained the same, further suggesting the strong effects of alcohol intake on ESCC mortality and indicating that our results was stable and robust. Similar results were obtained when the studies not including information of stage and severity of esophageal cancer were excluded. The findings from our study are consistent with the results from a previous meta-analysis by Fahey et al. [16], though the contrast groups were different between two studies. To examine the robustness of our results, we repeated the analysis by excluding the study one by one from the pooled results, and no significant change was observed for ESCC and EAC with the exception of excluding the study by Huang et al. [27], indicating the results our study obtained were stable. Omitting the study by Huang et al. [27] altered the positive association between alcohol consumption and risk of death in EC and ESCC to no association. This may be due to that the sample size of this study was the largest, therefore the weight of the study was relatively large when calculating the pooled results, indicating that more studies with large scale samples are needed.

Our results of meta-analysis also indicated that intake of dietary folate was associated with 59\% reduced risk of esophageal cancer-specific mortality among ESCC patients. 
Table 2 Hazard ratios (HRs) with 95\% confidence intervals (Cls) for alcohol consumption and mortality of esophageal cancer by histological type

\begin{tabular}{|c|c|c|c|c|c|c|}
\hline \multirow[t]{2}{*}{ Study ID ${ }^{a}$} & \multirow[t]{2}{*}{$\begin{array}{l}\text { Crude } \\
\text { HR }(95 \% \mathrm{Cl})^{\text {b }}\end{array}$} & \multirow[t]{2}{*}{$\begin{array}{l}\text { Adjusted } \\
\text { HR }(95 \% \mathrm{Cl}){ }^{\text {b }}\end{array}$} & \multicolumn{2}{|c|}{$\begin{array}{l}\text { Heterogeneity for } \\
\text { pooled crude HR }\end{array}$} & \multicolumn{2}{|c|}{$\begin{array}{l}\text { Heterogeneity for } \\
\text { pooled adjusted HR }\end{array}$} \\
\hline & & & $\overline{P^{2}(\%)}$ & $P$ & $\overline{P^{2}(\%)}$ & $P$ \\
\hline$\overline{\mathrm{EC}}$ & & & I & I & 4.2 & 0.352 \\
\hline Huang et al. [27] & & $1.46(1.19,1.79)$ & & & & \\
\hline Samadi et al. [33] & & $7.51(0.82,69.10)$ & & & & \\
\hline Park et al. [28] & & $1.44(0.81,2.55)$ & & & & \\
\hline pooled estimates & & $1.48(1.19,1.84)$ & & & & \\
\hline ESCC & & & 77.8 & 0.001 & 66.9 & 0.010 \\
\hline Huang et al. [27] & & $1.37(1.11,1.70)$ & & & & \\
\hline Ma et al. [15] & & $1.58(1.21,2.07)$ & & & & \\
\hline Shitara et al. [26] & $0.87(0.65,1.17)$ & $0.85(0.61,1.18)$ & & & & \\
\hline Sundelof et al. [14] & & $0.60(0.30,1.40)$ & & & & \\
\hline Thrift et al. [29] & $2.51(1.63,3.85)$ & $2.08(1.18,3.69)$ & & & & \\
\hline Trivers et al. [23] & $1.77(0.93,3.35)$ & & & & & \\
\hline Wu et al. [32] & & $1.30(1.01,1.67)$ & & & & \\
\hline Jing et al. [25] & $1.42(0.83,1.84)$ & & & & & \\
\hline Lu et al. [24] & $1.02(0.61,1.72)$ & & & & & \\
\hline pooled estimates & $1.27(1.06,1.53)$ & $1.26(1.01,1.60)$ & & & & \\
\hline EAC & & & / & / & 0.0 & 0.960 \\
\hline Sundelof et al. [14] & & $1.00(0.50,1.70)$ & & & & \\
\hline Thrift et al. [31] & & $1.02(0.64,1.64)$ & & & & \\
\hline Trivers et al. [23] & $1.08(0.81,1.44)$ & & & & & \\
\hline pooled estimates & & $1.01(0.70,1.47)$ & & & & \\
\hline
\end{tabular}

a EC esophageal cancer, ESCC esophageal squamous cell carcinoma, EAC esophageal adenocarcinoma, $H R$ hazard ratio, $C I$ confidence interval

${ }^{b}$ The effect was estimated by comparing the highest with the lowest consumption of alcohol

\begin{tabular}{|c|c|c|}
\hline Study & Effect size $(95 \% \mathrm{Cl})$ & Weight $\%$ \\
\hline \multicolumn{3}{|l|}{ EC } \\
\hline Huang et al. (2014) & $1.46(1.19,1.79)$ & 12.78 \\
\hline Samadi et al. (2007) & $7.51(0.82,69.10)$ & 0.34 \\
\hline Park et al. (2006) & $1.44(0.81,2.55)$ & 4.06 \\
\hline Subtotal $(\mathrm{I}-$ squared $=4.2 \%, p=0.352)$ & $1.48(1.19,1.84)$ & 17.18 \\
\hline ESCC & & \\
\hline Huang et al. (2014) & $1.37(1.11,1.70)$ & 12.43 \\
\hline Ma et al. (2016) & $1.58(1.21,2.07)$ & 10.41 \\
\hline Shitara et al. (2010) & $0.85(0.61,1.18)$ & 8.51 \\
\hline Sundelof et al. (2008) & $0.60(0.30,1.40)$ & 2.50 \\
\hline Thrift et al. (2012) & $2.08(1.18,3.69)$ & 4.10 \\
\hline Trivers et al. (2005) & $1.77(0.93,3.35)$ & 3.40 \\
\hline Wu et al. (2013) & $1.30(1.01,1.67)$ & 11.01 \\
\hline Jing et al. (2012) & $1.42(0.83,1.84)$ & 6.82 \\
\hline Lu et al. (2011) & $1.02(0.61,1.72)$ & 4.74 \\
\hline \multirow[t]{2}{*}{ Subtotal $(I-$ squared $=53.0 \%, p=0.030)$} & $1.29(1.07,1.55)$ & 63.92 \\
\hline \multirow{2}{*}{\multicolumn{3}{|c|}{ EAC }} \\
\hline & & \\
\hline Sundelof et al. (2008) & $1.00(0.50,1.70)$ & 3.67 \\
\hline Thrift et al. (2012) & $1.02(0.64,1.64)$ & 5.46 \\
\hline Trivers et al. (2005) & $1.08(0.81,1.44)$ & 9.78 \\
\hline Subtotal $(I-$ squared $=0.0 \%, p=0.963)$ & $1.05(0.84,1.32)$ & 18.90 \\
\hline
\end{tabular}

Fig. 4 Forest plot of association between alcohol consumption (highest vs. lowest) and risk of mortality by cancer type. Abbreviation: EC, esophageal cancer; EAC, esophageal adenocarcinoma; ESCC, esophageal squamous cell carcinoma 


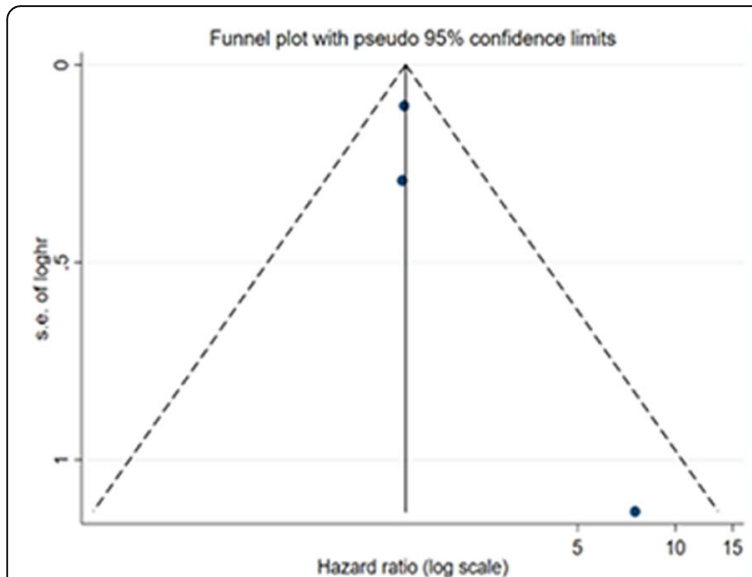

(a) Esophageal cancer

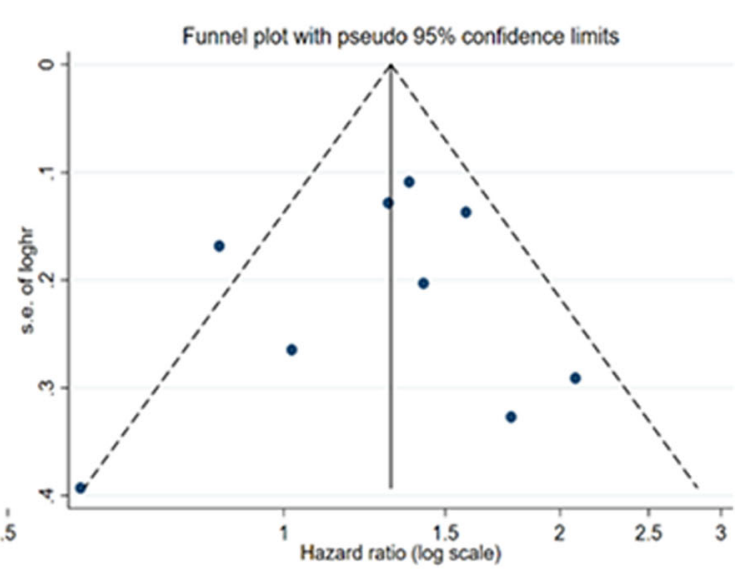

(b) Esophageal squamous cell carcinoma

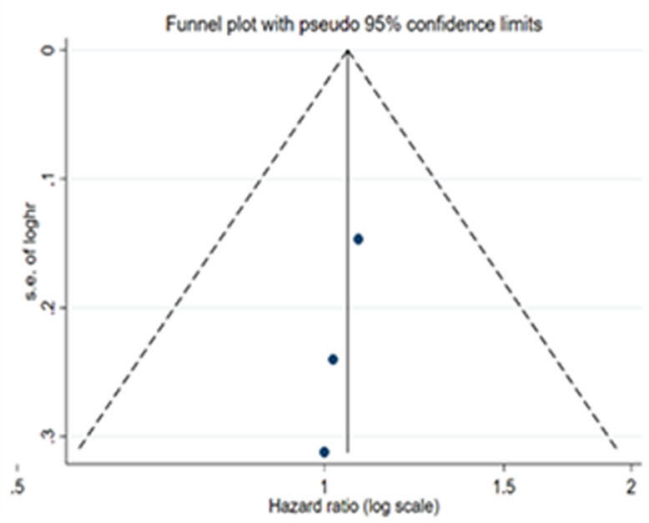

(c) Esophageal adenocarcinoma

Fig. 5 The funnel plot with Pseudo 95\% confidence limits on alcohol consumption and risk of mortality by cancer type

This finding is consistent with findings on other cancers $[36,37]$. Folate metabolites have become diagnostic and therapeutic targets for several types of cancers in recent years $[38,39]$. The possible mechanism maybe due to that folate deficiency indirectly affects DNA and RNA methylation, thereby alters the expression of tumor suppressor genes and proto-oncogenes [40, 41]. However, only two studies focused on effects of dietary folate intake on EC mortality, and all were carried out in China with small sample size. Thus, replication of our results in other large studies in different countries is warranted.

The evidence for other dietary components is limited. Lignans was found to reduce risk of all-cause mortality of ESCC by $42 \%$ [12], while positive association between the other two factors, sugary beverages and preserved vegetables, and esophageal cancer survival was revealed $[13,30]$. Sugar in food can lead to awful disease progression through increased inflammation. The inflammation can be caused by oxidative stress, which ultimately accelerates DNA damage and elevates levels of interleukin-cytokines and other pro-inflammatory molecules [42]. N-nitroso compounds widely existing in processed foods (eg. preserved vegetables) may play an important role in tumor progression. $\mathrm{N}$-nitroso compounds give rise to excessive expression of cyclinE 1, cyclinD 1, transform growth factor $\alpha$ and epidermal growth factor receptor in esophageal tissues, thus enhance cancer progression [43]. Anti-cancer effects of phytochemicals like lignans are mainly through estrogen/anti-estrogen activity, anti-proliferation or apoptosis, prevention of oxidation, induction of cell cycle arrest, regulation of changes in host immune system, anti-inflammatory activity and cell signal transduction [44].

This study has some strengths. First, the literature retrieval was from multiple databases and the selection was determined by independent reviewers, which was helpful to avoid literature omission. Second, we included studies according to the strict inclusion and exclusion criteria, which may augment the validity of our findings. Third, sensitivity analyses yielded similar results, indicating the stability of our findings. 
There were also some limitations in this study. There were only 15 studies included; most of them focused on alcohol consumption and only five focused on other dietary components; pooling results from limited evidence may influence the stability of our results, though the power of random effect models in our study is fairly strong and sensitivity analyses yield similar results. Consuming large amounts of fruits and vegetables after diagnosis could reduce the mortality of cancer and diets before diagnosis may reflect the changes in taste or appetite attributable to cancer [45]. Besides, cancer patients may follow the doctor's advice to change their diets in order to obtain better prognosis. However, dietary behaviors in this systematic review and metaanalysis were all pre-diagnostic, the roles of postdiagnostic dietary intake in prognosis of esophageal cancer are unclear.

\section{Conclusion}

In summary, this review with limited evidence suggested that folate intake was associated with a reduced risk of esophageal cancer-specific mortality for ESCC, whereas alcohol consumption was associated with increased risk of mortality for ESCC. More studies are needed to investigate effect of dietary factors, especially post-diagnosis dietary consumption, on esophageal cancer prognosis.

\section{Supplementary information}

Supplementary information accompanies this paper at https://doi.org/10. 1186/s12885-020-06767-8.

Additional file 1: Figure S1. Summary of sensitivity analyses of alcohol consumption and mortality among (a) EC (b) ESCC (c) EAC. Abbreviation: $H R$, hazard ratio; $\mathrm{Cl}$, confidence interval; EC, esophageal cancer; EAC, esophageal adenocarcinoma; ESCC, esophageal squamous cell carcinoma.

\section{Abbreviations}

Cl: Confidence interval; EC: Esophageal cancer; ESCC: Esophageal squamous cell carcinoma; EAC: Esophageal adenocarcinoma; HR: Hazard ratio HR; NOS: Newcastle-Ottawa Scale

\section{Acknowledgments}

We would like to show our thanks to the authors of original published researches; their work achievement is the precondition of our study.

\section{Authors' contributions \\ XDL conceived and designed this study; LPS, LBY, and ZZL conducted the research, including the literature search, quality assessment, and data extraction; WZ and CXZ assisted with the quality assessments; LPS performed the statistical analysis; LPS and XDL wrote the manuscript; XDL, WZ, CXZ, YMC, XQL and edited and reviewed the manuscript. All authors have read and approved the manuscript, and ensure that this is the case.}

\section{Funding}

This study was supported by the Guangdong Basic and Applied Basic Research Foundation (No.2019A15150115990). The funders had no role in the design, analysis, or writing of this manuscript.

\section{Availability of data and materials}

This study is a systematic review and meta-analysis, the data was extracted from published research. The data is available by contacting corresponding author or extracting from original published research.

\section{Ethics approval and consent to participate}

Ethical approval for this study was obtained from Ethical Review Committee for Biomedical Research, School of Public Health, Sun Yat-sen University. The study was performed in accordance with the Declaration of Helsinki. The study is a systematic review and meta-analysis and no patients involved.

\section{Consent for publication}

This study did not contain any individual person's data.

\section{Competing interests}

All authors declared that they have no conflicts of interest.

\section{Author details}

'Department of Epidemiology, School of Public Health, Sun Yat-sen University, Guangzhou, China. ${ }^{2}$ Department of Pediatric Surgery, the Sixth Affiliated Hospital, Sun Yat-sen University, Guangzhou, China. ${ }^{3}$ Department of Radiology, the Third Affiliated Hospital, Sun Yat-sen University, Guangzhou, China. ${ }^{4}$ Department of Public Health, Faculty of Medicine, Hokkaido University, Sapporo, Japan. ${ }^{5} \mathrm{JC}$ School of Public Health and Primary care, the Chinese University of Hong Kong, Hong Kong, China.

Received: 10 November 2019 Accepted: 20 March 2020

Published online: 06 April 2020

\section{References}

1. Bray F, Ferlay J, Soerjomataram I, Siegel RL, Torre LA, Jemal A. Global cancer statistics 2018: GLOBOCAN estimates of incidence and mortality worldwide for 36 cancers in 185 countries. CA Cancer J Clin. 2018;68(6):394-424.

2. Malhotra GK, Yanala U, Ravipati A, Follet M, Vijayakumar M, Are C. Global trends in esophageal cancer. J Surg Oncol. 2017;115(5):564-79.

3. Siegel RL, Miller KD, Jemal A. Cancer statistics, 2019. CA Cancer J Clin. 2019; 69(1):7-34.

4. Anderson LA, Tavilla A, Brenner H, Luttmann S, Navarro C, Gavin AT, Holleczek B, Johnston BT, Cook MB, Bannon F, et al. Survival for oesophageal, stomach and small intestine cancers in Europe 1999-2007: results from EUROCARE-5. Eur J Cancer. 2015;51(15):2144-57.

5. Zeng H, Zheng R, Guo Y, Zhang S, Zou X, Wang N, Zhang L, Tang J, Chen J, Wei K, et al. Cancer survival in China, 2003-2005: a population-based study. Int J Cancer. 2015;136(8):1921-30.

6. Vendrely V, Launay V, Najah H, Smith D, Collet D, Gronnier C. Prognostic factors in esophageal cancer treated with curative intent. Digestive Liver Disease. 2018:50(10):991-6.

7. Nguyen Ba N, Lv P, Zhao W-E. Suppressive effects of lycopene and betacarotene on the viability of the human esophageal squamous carcinoma cell line EC109. Oncol Lett. 2018;15(5):6727-32.

8. Burden S, Sremanakova J, Jones D, Todd C. Dietary interventions for cancer survivors. Proc Nutr Soc. 2018;78(1):135-45.

9. Chen F, Fang J, Wang H, Song T, Zhu W, Wu M, Wu Y. Effects of nutritional support on short-term clinical outcomes and immune response in unresectable locally advanced oesophageal squamous cell carcinoma. Eur J Cancer Care. 2018;27(2):e12818.

10. Healy LA, Ryan A, Doyle SL, Bhuachalla EB, Cushen S, Segurado R, Murphy T, Ravi N, Donohoe $\mathrm{CL}$, Reynolds JV. Does prolonged enteral feeding with supplemental Omega-3 fatty acids impact on recovery post-esophagectomy results of a randomized double-blind trial. Ann Surg. 2017;266(5):720-8.

11. Matsumoto $H$, Okamoto $Y$, Kawai A, Ueno D, Kubota H, Murakami H, Higashida M, Hirai T. Prognosis prediction for postoperative esophageal Cancer patients using Onodera's prognostic nutritional index. Nutrit Cancer Int J. 2017;69(6):849-54.

12. Miles FL, Chang SC, Morgenstern H, Tashkin D, Rao JY, Cozen W, Mack T, Lu QY, Zhang ZF. Association of sugary beverages with survival among patients with cancers of the upper aerodigestive tract. Cancer Causes Control. 2016;27(11):1293-300.

13. Petrick UL, Steck SE, Bradshaw PT, Trivers KF, Abrahamson PE, Engel LS, He K, Chow WH, Mayne ST, Risch HA, et al. Dietary intake of flavonoids and 
oesophageal and gastric cancer: incidence and survival in the United States of America (USA). Br J Cancer. 2015;112(7):1291-300.

14. Sundelof M, Lagergren J, Ye W. Patient demographics and lifestyle factors influencing long-term survival of oesophageal cancer and gastric cardia cancer in a nationwide study in Sweden. Eur I Cancer (Oxford, England: 1990). 2008;44(11):1566-71.

15. Ma Q, Liu W, Jia R, Long H, Zhang L, Lin P, Zhao H, Ma G. Alcohol and survival in ESCC: prediagnosis alcohol consumption and postoperative survival in lymph node-negative esophageal carcinoma patients. Oncotarget. 2016;7(25):38857-63.

16. Fahey PP, Mallitt KA, Astell-Burt T, Stone G, Whiteman DC. Impact of prediagnosis behavior on risk of death from esophageal cancer: a systematic review and meta-analysis. Cancer Causes Control. 2015;26(10):1365-73.

17. Moher D, Liberati A, Tetzlaff J, Altman DG, Group P. Preferred reporting items for systematic reviews and meta-analyses: the PRISMA statement. BMJ. 2009;339:b2535.

18. Stang A. Critical evaluation of the Newcastle-Ottawa scale for the assessment of the quality of nonrandomized studies in meta-analyses. Eur J Epidemiol. 2010;25(9):603-5.

19. Rotenstein $L S$, Ramos MA, Torre M, et al. Prevalence of depression, depressive symptoms, and suicidal ideation among medical students: a systematic review and meta-analysis. JAMA. 2016;316(21):2214-36.

20. Higgins JPT, Thompson SG, Deeks JJ, Altman DG. Measuring inconsistency in meta-analyses. BMJ (Clinical research ed). 2003;327(7414):557-60.

21. Sedgwick P. Meta-analyses: how to read a funnel plot. Br Med J. 2013;346: f1342.

22. Harrer $M$, Cuijpers $P$, Furukawa TA, Ebert DD. Doing Meta-Analysis in R: A Hands-on Guide. 2019. https://doi.org/10.5281/zenodo.2551803. Available at https://bookdown.org/MathiasHarrer/Doing_Meta_Analysis_in_R/.

23. Trivers KF, de Roos AJ, Gammon MD, Vaughan TL, Risch HA, Olshan AF, Schoenberg JB, Mayne ST, Dubrow R, Stanford JL, et al. Demographic and lifestyle predictors of survival in patients with esophageal or gastric cancers. Clin Gastroenterol Hepatol. 2005;3(3):225-30

24. Lu C, Xie H, Wang F, Shen H, Wang J. Diet folate, DNA methylation and genetic polymorphisms of MTHFR C677T in association with the prognosis of esophageal squamous cell carcinoma. BMC Cancer. 2011:11:91.

25. Jing C, Huang Z, Duan $Y$, Xiao X, Zhang R, Jiang J. Folate intake, methylenetetrahydrofolate reductase polymorphisms in association with the prognosis of esophageal squamous cell carcinoma. Asian Pacific J Cancer Prevention. 2012;13(2):647-51.

26. Shitara K, Matsuo K, Hatooka S, Ura T, Takahari D, Yokota T, Abe T, Kawai H, Tajika M, Kodaira T, et al. Heavy smoking history interacts with chemoradiotherapy for esophageal cancer prognosis: a retrospective study. Cancer Sci. 2010;101(4):1001-6.

27. Huang Q, Luo K, Yang H, Wen J, Zhang S, Li J, Ela Bella A, Liu Q, Yang F, Zheng $Y$, et al. Impact of alcohol consumption on survival in patients with esophageal carcinoma: a large cohort with long-term follow-up. Cancer Sci. 2014;105(12):1638-46.

28. Park SM, Lim MK, Shin SA, Yun YH. Impact of prediagnosis smoking, alcohol, obesity, and insulin resistance on survival in male cancer patients: National Health Insurance Corporation Study. J Clin Oncol. 2006;24(31):5017-24.

29. Thrift AP, Nagle CM, Fahey PP, Russell A, Smithers BM, Watson DI, Whiteman DC. The influence of prediagnostic demographic and lifestyle factors on esophageal squamous cell carcinoma survival. Int J Cancer. 2012;131(5): E759-68.

30. Shi F, Yan F, Jin M, Chang H, Zhou Q, Zhao L, Hu Z, Song Q, Li J, He Y, et al. Pre-diagnosis consumption of preserved vegetables and prognosis of invasive oesophageal squamous cell carcinoma: a prospective cohort study in one high-risk area in China. J Int Med Res. 2018;46(10):4306-14.

31. Thrift AP, Nagle CM, Fahey PP, Smithers BM, Watson DI, Whiteman DC Predictors of survival among patients diagnosed with adenocarcinoma of the esophagus and gastroesophageal junction. Cancer Causes Control. 2012;23(4):555-64.

32. Wu IC, Wu CC, Lu CY, Hsu WH, Wu MC, Lee JY, Chou SH, Lee JM, Chou YP, Wu DC, et al. Substance use (alcohol, areca nut and cigarette) is associated with poor prognosis of esophageal squamous cell carcinoma. PLoS One. 2013;8(2):e55834.

33. Samadi F, Babaei M, Yazdanbod A, Fallah M, Nouraie M, Nasrollahzadeh D, Sadjadi A, Derakhshan MH, Shokuhi B, Fuladi R, et al. Survival rate of gastric and esophageal cancers in Ardabil province, north-west of Iran. Archives Iran Med. 2007;10(1):32-7.
34. World Cancer Research Fund/American Insititue for Cancer Research. Continuous Updated Project Expert Report 2018. Diet, Nutrition, Physical Activity and Oesophageal Cancer. 2018. Available at https://www.wcrf.org/ dietandcancer/oesophageal-cancer.

35. VanderWeele TJ, Shpitser I. On the definition of a confounder. Ann Stat. 2013:41(1):196-220.

36. Sato F, Ito H, Oze I, Tajima K, Watanabe M, Hosono S, Kawakita D, Tanaka H, Matsuo K, Murakami S, et al. Association between dietary folate intake and clinical outcome in head and neck squamous cell carcinoma. Ann Oncol. 2011;23(1):186-92.

37. Li B, Lu Y, Wang L, Zhang CX. Folate intake and breast cancer prognosis: a meta-analysis of prospective observational studies. Eur J Cancer Prev. 2015; 24(2):113-21.

38. Konn M, Asai A, Kawamoto K, Nishida N, Satoh T, Doki Y, Mori M, Ishii H. The one-carbon metabolism pathway highlights therapeutic targets for gastrointestinal cancer (review). Int J Oncol. 2017;50(4):1057-63.

39. Koseki J, Konno M, Asai A, Colvin H, Kawamoto K, Nishida N, Sakai D, Kudo T, Satoh T, Doki Y, Mori M, Ishii H. Enzymes of the one-carbon folate metabolism as anticancer targets predicted by survival rate analysis. Sci Rep. 2018;8(1):303.

40. Liew SC: Folic acid and diseases - supplement it or not? Revista da Associacao Medica Brasileira (1992) 2016, 62(1):90-100.

41. Rai V. Folate pathway gene MTHFR C677T polymorphism and risk of lung cancer in Asian populations. Asian Pacific J Cancer Prevention. 2014;15(21): 9259-64.

42. Johnson RJ, Sanchez-Lozada LG, Nakagawa T. The effect of fructose on renal biology and disease. J Am Soc Nephrol. 2010;21(12):2036-9.

43. Liston BW, Gupta A, Nines R, Carlton PS, Kresty LA, Harris GK, Stoner GD. Incidence and effects of ha-ras codon $12 \mathrm{G} \rightarrow$ a transition mutations in preneoplastic lesions induced by $\mathrm{N}$-nitrosomethylbenzylamine in the rat esophagus. Mol Carcinog. 2001;32(1):1-8.

44. Veeramuthu D, Raja WRT, Al-Dhabi NA, Savarimuthu I: Flavonoids: Anticancer Properties. Flavonoids - From Biosynthesis to Human Health Goncalo C. Justino, IntechOpen; 2017

45. Peng $C$, Luo W-P, Zhang C-X. Fruit and vegetable intake and breast cancer prognosis: a meta-analysis of prospective cohort studies. Br J Nutr. 2017; 117(5):737-49.

\section{Publisher's Note}

Springer Nature remains neutral with regard to jurisdictional claims in published maps and institutional affiliations.

Ready to submit your research? Choose BMC and benefit from:

- fast, convenient online submission

- thorough peer review by experienced researchers in your field

- rapid publication on acceptance

- support for research data, including large and complex data types

- gold Open Access which fosters wider collaboration and increased citations

- maximum visibility for your research: over $100 \mathrm{M}$ website views per year

At $\mathrm{BMC}$, research is always in progress.

Learn more biomedcentral.com/submissions 